\title{
Dynamical Regional Downscaling Using the JRA-55 Reanalysis (DSJRA-55)
}

\author{
Nobuyuki Kayaba ${ }^{1,2}$, Takashi Yamada ${ }^{1}$, Syugo Hayashi ${ }^{2}$, Kazutoshi Onogi ${ }^{1}$, Shinya Kobayashi ${ }^{1,2}$, \\ Koichi Yoshimoto ${ }^{1,2}$, Kenji Kamiguchi ${ }^{1}$, and Kazuya Yamashita ${ }^{1}$ \\ ${ }^{1}$ Climate Prediction Division, Japan Meteorological Agency \\ ${ }^{2}$ Meteorological Research Institute, Japan Meteorological Agency
}

\begin{abstract}
The Japan Meteorological Agency (JMA) completed its second global atmospheric reanalysis, the Japanese 55-year Reanalysis (JRA-55). However, the horizontal spatial resolution of JRA55, TL319 (about $55 \mathrm{~km}$ ), is insufficient for representing the hilly topography of the Japanese islands. Therefore, to reproduce extreme events caused by the hilly topography and their long-term climatological change in Japan, JMA has conducted a dynamical regional downscaling, called DSJRA-55, based on JMA's operational mesoscale model, which has a horizontal resolution of 5 $\mathrm{km}$. DSJRA-55 receives its initial field and boundary conditions from the JRA-55 reanalysis. DSJRA-55 is historically the first products in the world that covers very long term for 55 years with very high resolution in $5 \mathrm{~km}$. Furthermore, DSJRA-55 does not perform data assimilation; instead, initial field and boundary conditions are given at frequent intervals to the downscaled model and short-range forecasts are performed. Then, successive forecasts are connected continuously to create the DSJRA-55 product. In early evaluation results, DSJRA-55 was able to reproduce observed temperature and precipitation during 1958-2012. Although it showed a systematic temperature bias in some regions and seasons and it underestimated the frequencies of heavy-rain days and heavy-rain hours, DSJRA-55 reproduced the overall distribution of orographic precipitation well. DSJRA-55 is therefore expected to be useful for analyzing past extreme events and for statistical studies of long-term climate.
\end{abstract}

(Citation: Kayaba, N., T. Yamada, S. Hayashi, K. Onogi, S. Kobayashi, K. Yoshimoto, K. Kamiguchi, and K. Yamashita, 2016: Dynamical regional downscaling using the JRA-55 reanalysis (DSJRA-55). SOLA, 12, 1-5, doi:10.2151/sola.2016-001.)

\section{Introduction}

Reanalysis of past observations using a consistent, state-ofthe-art data assimilation system can produce a high-quality gridded dataset of meteorological variables covering several decades in a physically consistent, spatiotemporally regular manner, even for regions where observations are sparse or lacking.

The Japanese 25-year Reanalysis (JRA-25) was jointly conducted by the Japan Meteorological Agency (JMA) and the Central Research Institute of Electric Power Industry (Onogi et al. 2007). Continuously, JMA completed a second Japanese global atmospheric reanalysis, called JRA-55, covering the 55 years from 1958 to 2012 (Kobayashi et al. 2015). JRA-55 is the world's first long-term reanalysis covering more than 50 years produced by using a four-dimensional variational (4D-var) data assimilation system. The quality of JRA-55, compared with JRA-25, is much improved by reductions in both systematic biases and unnatural jumps in time series due to changes in observation systems.

JRA-55 has a horizontal resolution of TL319 (about $55 \mathrm{~km}$ ). However, to represent past climate and to evaluate the influence of global warming in Japan, data with a much higher resolution are required. Therefore, JMA conducted a dynamical regional downscaling based on the JRA-55 data called DSJRA-55. DSJRA-55, which was completed in January 2015, covers the same years as

Corresponding author: Nobuyuki Kayaba, Japan Meteorological Agency, Otemachi 1-3-4, Chiyodaku, Tokyo 100-8122 Japan. Email: n-kayaba@ met.kishou.go.jp. (C2016, the Meteorological Society of Japan. those covered by JRA- 55 .

As this kind of regional downscaling study, Kanamitsu and Kanamaru (2007) carried out Fifty-Seven-Year California Reanalysis Downscaling at $10 \mathrm{~km}$ (CaRD10). Kei Yoshimura (private communications) produced the similar dataset using CaRD10 system for Japan region in $10 \mathrm{~km}$ resolution. DSJRA-55 is historically the first products in the world with very fine resolution in $5 \mathrm{~km}$. DSJRA-55 covers as the same 55 years as that of JRA-55 global reanalysis, and the world first product using non-hydrostatic model. $5 \mathrm{~km}$ resolution is much better to represent fine orography to distinguish small-scale ridges and valleys than $10 \mathrm{~km}$ resolution. Non-hydrostatic model is required for $5 \mathrm{~km}$ resolution because non-hydrostatical phenomena should be considered in such fine horizontal resolution.

Here we outline the DSJRA-55 system, and present the results of some early evaluations.

\section{The DSJRA-55 system}

\subsection{Preliminary downscaling experiments}

The Meteorological Research Institute (MRI) of JMA carried out a preliminary downscaling study with one-year time integration method. The results of this preliminary study, however, revealed large temperature errors, especially in snow-covered areas in winter. Past individual meteorological events were not well reproduced because synoptic-scale patterns were sometimes inconsistent with observations (see Fig. S1). Long-term time integration method is not adequate for reproducing individual events.

In analyses of past climate, however, an important priority is to reproduce individual events with high consistency with observational data. For the purpose, the DSJRA-55 system consists of non-hydrostatic downscaling model (NHDSM) based on JMA's operational MSM (Saito et al 2006).

\subsection{Features of the DSJRA-55 system} tures.

The DSJRA-55 system has the following three significant fea-

1. In DSJRA-55, initial conditions are renewed at frequent intervals, so long-term integration is not necessary. An initial condition is given every $6 \mathrm{~h}$ from JRA-55 6-hourly reanalysis data, and a 12-h forecast using these data is performed every $6 \mathrm{~h}$.

2. Because long-term integration is not performed, a land surface model for a climate model is not used. Instead, the surface boundary conditions are set using JRA-55 land surface analysis data and COBE-SST (Ishii et al. 2005) for sea surface temperature.

3. The DSJRA-55 domain is mapped using the projection method of the operational MSM (Fig. 1a).

With regard to point 1, although the frequent (6-hourly) replacement of initial conditions reduces the synoptic error, precipitation can be underestimated because the initial conditions include no cloud physical data. As a result, a spin-up time of 3 to $6 \mathrm{~h}$ is necessary to reproduce the appropriate precipitation. Therefore, the DSJRA-55 system employs a nested model configuration (Fig. 1b). First, a 15-km-resolution version of the MSM produces an hourly initial and boundary condition for a 5-km-resolution MSM with a 12-h forecast from the JRA-55 6-hourly initial and boundary condition. Next, the 5-km-resolution MSM calculates a 9-h forecast with the 3-12 $\mathrm{h}$ initial and boundary condition produced by the $15-\mathrm{km}-$ resolution model. Finally the $6-12 \mathrm{~h}$ forecast data from the JRA-55 initial time are used as the DSJRA-55 fore- 
(a)

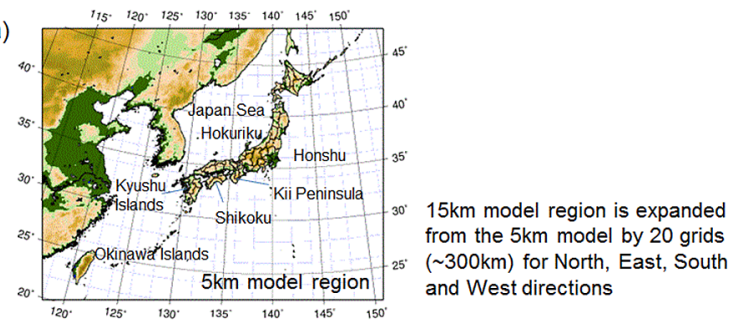

(b)

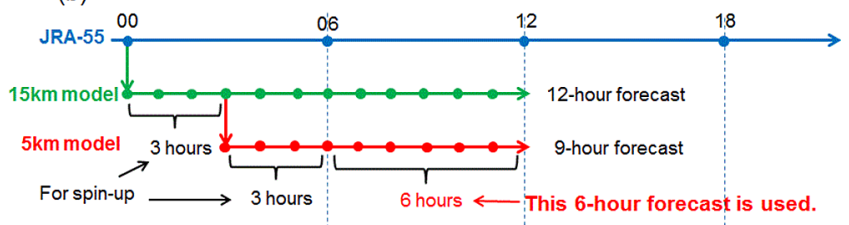

Fig. 1. Outline of the DSJRA-55 system. (a) Map of the $5 \mathrm{~km}$ MSM domain used for DSJRA-55. (b) Timelines illustrating the calculation method. Initial conditions are obtained every $6 \mathrm{~h}$ from the JRA-55 6-hourly reanalysis, and a $12-\mathrm{h}$ forecast is performed every $6 \mathrm{~h}$. Data are output every hour. The first $6 \mathrm{~h}$ are used for spin-up, and successive sets of 7- to 12-h data are connected to make the final product.

cast products. Namely, the successive $6-12 \mathrm{~h}$ forecast products produced by the 3-9 $\mathrm{h}$ forecast from $5 \mathrm{~km}-\mathrm{MSM}$ are continuously connected to produce a long-term climate dataset. As a result, the forecast error includes only the error of the MSM 6- to 12-h forecasts. This model system generates high-quality and high-resolution climate data for Japan.

\subsection{Outline of the NHDSM}

The NHDSM used in DSJRA-55 is based on JMA's latest operational MSM (as of November 2012); thus, all parameterizations implemented in the MSM at that time are also implemented in the DSJRA-55 system. The DSJRA-55 model domain is also the same as the domain of the operational MSM at that time (although the MSM domain was subsequently enlarged on 28 March 2013). The domain of the $15-\mathrm{km}$ model, however, is larger by $\sim 300 \mathrm{~km}$ (twenty $15-\mathrm{km}$ grids) in each of the four cardinal directions. In addition to the three major features listed in Section 2.2, the DSJRA-55 system incorporates the following two improvements.

4. Concentrations of greenhouse gases (GHGs; $\mathrm{CO}_{2}, \mathrm{CH}_{4}$, and $\mathrm{N}_{2} \mathrm{O}$ ) change over time. The concentrations of GHGs observed at Ryori, Minami-Torishima, and Yonagunijima stations of JMA are used. GHG data for years without Japanese observational data are taken from JRA-55 as a reference.

5. The effect of historical land-use changes, such as urbanization, is taken into account. The National Land Numerical Information product of the Geospatial Information Authority of Japan is used to define land-use parameters in each model grid cell. The applied land-use parameters also change with time: version 1976 is used for 1958 to 1981 , version 1987 for 1982 to 1989 , version 1991 for 1990 to 1994, version 1997 for 1995 to 2001, and version 2006 for 2002 to 2012.

The incorporation of these two improvements produces a more consistent climate dataset that reflects changes due to global warming and urbanization and allows direct comparisons with observed climate changes.

Like the MSM on which it is based, as physical parameterizations, DSJRA-55 uses the Kain-Fritsch scheme for cumulus convection, a partial condensation scheme for radiative clouds, and an improved Mellor-Yamada Level 3 scheme for physical processes. Details are available in JMA (2013b).

\section{Evaluation of DSJRA-55}

Expected uses of DSJRA-55 include the precise investigation of extreme events such as orographic heavy rain. In this section, we evaluate how well DSJRA-55 reproduces temporal and spatial variations of temperature and precipitation in relation to the temperature and precipitation climatologies and discuss some possible applications of DSJRA-55.

In Sections 3 and 4, DSJRA-55 is abbreviated as DS for simplicity and to avoid confusion between JRA-55 and DSJRA-55.

\subsection{Reproducibility of temperature and precipitation climatologies a. Temperature}

Annually averaged temperature anomalies during 55 years (1958-2012) among 51 and 15 selected JMA long-term observatories(available since 1898), JRA-55, and DS for each are compared in Fig. 2. The 51 selected JMA long-term observatories (available since 1898) all for temperature monitoring, otherwise the 15 observatories were selected as appropriate for monitoring global warming with little effect of urbanization. Only land surface temperatures in Japan were considered (i.e., temperatures in grid cells with $>50 \%$ land). The JRA-55 gridded temperature data are weighted averages along latitude. The DS temperatures are the average of 14,080 grid cells. The long-term trend is captured well and is similar in all three datasets. The results show high correlations between the 51-station and both JRA-55 $(r=0.98)$ and DS $(r=0.92)$, and between the 15 -station and both JRA-55 $(r=0.99)$ and DS $(r=0.96)$. Before the 1970s, however, the DS trend was smaller, possibly owing to its incorporation of National Land Numerical Information. Because no land-use information was available before 1976, 1976 values were used for the land-use parameters in the period from 1958 to 1981 . As a result, overestimation of the effect of urbanization on temperature before 1976 may account for the smaller trend. We also examined seasonally averaged anomalies. Correlations of the 15-station with JRA-55 were high $(r=0.99)$ in all seasons. Although those with DS were also high, they varied slightly among seasons: spring, $r=0.97$; summer and autumn, $r=0.98$; and winter, $r=0.99$.

\section{b. Precipitation}

Annually averaged precipitation anomalies among 51 selected JMA long-term observatories (available since 1898) for precipitation monitoring, JRA-55, and DS are compared in Fig. 3. The gridded data averages were determined in the same way as those for temperature. The correlation coefficients between the 51-station and DS and JRA-55 were 0.91 and 0.87 , respectively. In summer, the correlation coefficients between the 51-station and DS and JRA-55 were 0.89 and 0.87 , respectively. The correlation coefficients were: in spring, 0.87 with DS and 0.86 with JRA-55; in autumn, 0.90 with DS and 0.91 with JRA-55; and in winter, 0.88 with DS and 0.90 with JRA-55. Thus, the reproducibility of seasonal precipitation by DS was improved compared with JRA-55 in summer. These results suggest that DS can reproduce well oro-
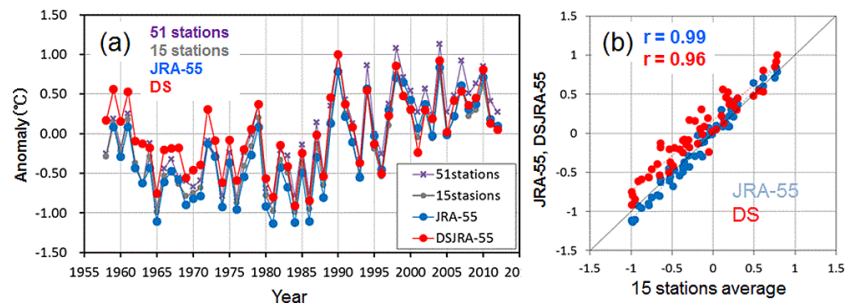

051 stations : Average of 51 stations obs. used for monitoring global warming 015 stations : Average of 15 stations obs. used for monitoring global warming with little effect of urbanization

OJRA-55 : Latitude weighted average for grids (ratio land/(land+sea) $>0.5$ ) in Japan ODS : Average of 14080 land grids in Japan

15 stations : Abashiri, Nemuro, Suttsu, Yamagata, Ishinomaki, Fushiki (Takaoka city) lida, Choshi, Sakai, Hamada, Hikone, Miyazaki, Tadotsu, Naze, Ishigakijima

Fig. 2. Annual mean temperature anomalies in Japan. (a) Time series of annual mean temperature anomalies of 15 observation stations (gray), JRA-55 (blue), and DSJRA-55 (red). (b) Scatter diagram comparing JRA55 and DSJRA-55 annual anomalies with the averaged annual anomalies of the 15 stations for the period from 1958 to 2012 . 
graphic precipitation and precipitation from a convective cloud in summer, but that in other seasons it might underestimate precipitation, perhaps owing to insufficient spin-up or to limitations of the lateral boundary conditions.

\subsection{Evaluation of the reproducibility of extreme precipitation events}

Because the horizontal resolution of DS is $5 \mathrm{~km}$, compared with $55 \mathrm{~km}$ in JRA-55, DS is expected to capture local heavy rain events well. The frequencies of heavy rain counts between JMA Automated Meteorological Data Acquisition System (AMeDAS; available since 1976) stations and DS are investigated. The frequencies of AMeDAS 1300 stations per 1000 stations and DS 14080 land grid cells per 1000 grids are compared during 19762012.

Reproducibility of the annual frequency of heavy rain per day (HRpD) was good $(r=0.93$ between DS and AMeDAS for $\geq 100 \mathrm{~mm}$ day $^{-1}$; Fig. 4). In fact, for HRpD with $\geq 200$ or $\geq 400 \mathrm{~mm} \mathrm{day}^{-1}$, the correlation coefficients between DS and AMeDAS were 0.76 and 0.66 , respectively. When we compared heavy rain per hour $(\mathrm{HRpH})$ between DS and AMeDAS, the correlation coefficients for $\geq 30$ or $\geq 50 \mathrm{~mm} \mathrm{~h}^{-1}$ were 0.69 and 0.46 , respectively.

Some of the DS grid cells are in mountainous areas with high precipitation, whereas most of the AMeDAS stations are in non-mountainous areas. Therefore, if DS reproduced precipitation

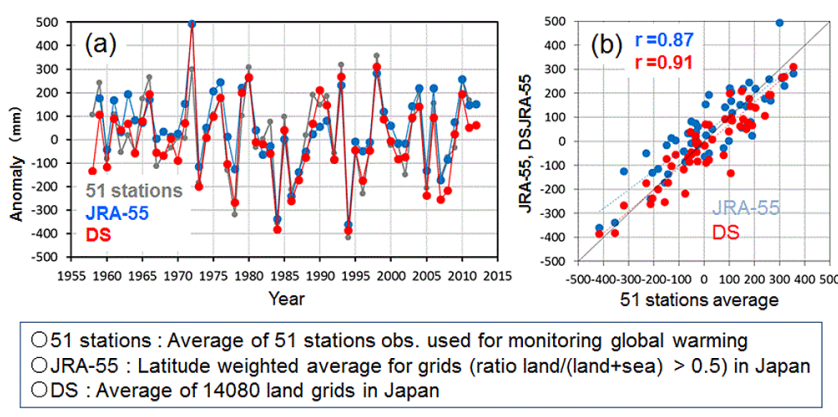

Fig. 3. Annual mean precipitation anomalies in Japan. (a) Time series of annual mean precipitation anomalies of 51 observation stations (gray), JRA-55 (blue), and DSJRA-55 (red). (b) Scatter diagram comparing JRA55 and DSJRA-55 annual anomalies with the averaged annual anomalies of the 51 stations for the period from 1958 to 2012. (a) Count of Heavy rain per day

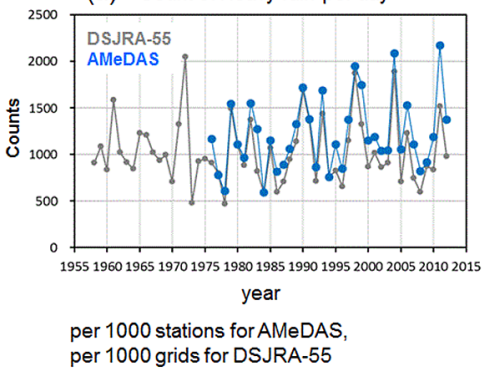

Definition :

heavy rain per day ( $\geqq 100 \mathrm{~mm}$ day $\left.^{-1}\right)$ heavy rain per hour ( $\geqq 30 \mathrm{~mm}$ hour $\left.{ }^{-1}\right)$

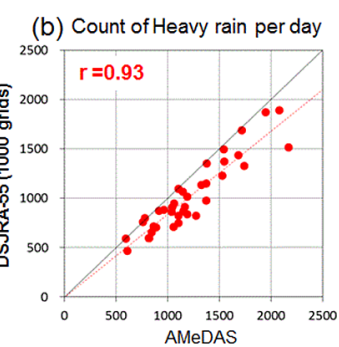

(c) Count of Heavy rain per hour

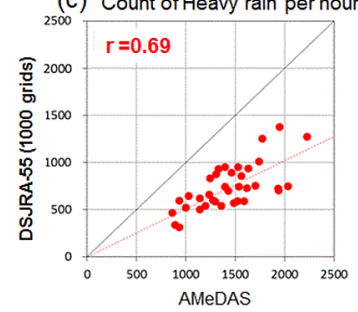

Fig. 4. Frequency of heavy rain. (a) Time series of the annual frequencies of HRpD per 1000 AMeDAS stations and per 1000 DSJRA-55 grids. Scatter diagrams of (b) HRpD frequency and (c) HRpH frequency versus AMeDAS data for the period from 1976 to 2012 . (HRpD, $\geq 100 \mathrm{~mm}^{-1}{ }^{-1}$; $\mathrm{HRpH}, \geq 30 \mathrm{~mm} \mathrm{~h}^{-1}$ ) realistically, more frequent extreme precipitation events should be found in DS than at the AMeDAS stations. These facts suggest that DS may underestimate orographic precipitation, especially the frequency of $\mathrm{HRpH}$. Thus, further evaluation of DS biases with regard to extreme precipitation events is needed.

\subsection{Evaluation of spatial biases in monthly means}

To evaluate the spatial accuracy of DS, monthly mean temperature and precipitation during the 30 years from 1981 to 2010 were compared with AMeDAS values. For this comparison, the value at each AMeDAS station was paired with that at the nearest grid point. The evaluations of winter (January) and summer (August) are discussed.

\section{a. Mean temperature}

In January, mean DS temperatures in inland eastern Japan were lower than those observed by AMeDAS (negative bias). In August, DS temperatures showed a negative bias in inland eastern Japan and a positive bias on the Pacific side of northern Japan (Fig. 5). These biases may reflect a systematic bias of the NHDSM or boundary conditions such as SST. Further investigations are required to detect the reasons for these biases.

\section{b. Precipitation}

JRA-55 reproduces precipitation more realistically than the Global Precipitation Climatology Project (GPCP; Adler et al. 2003) data, a monthly precipitation analysis which has a horizontal resolution of $2.5^{\circ}$ of latitude and longitude. DS reproduced much of orographic precipitation in mountainous areas, using the poorly represented orography in JRA-55.

In January, although DS underestimated precipitation in winter snowy regions, such as the Hokuriku region on the Japan Sea side of Honshu, compared with the AMeDAS observations, the distribution of precipitation reproduced by DS was much better than that by JRA-55. In and around the Okinawa Islands, DS precipitation was lower than that in both JRA-55 and the AMeDAS observations (Fig. S2).

In August, although in some areas DS precipitation was lower than at the AMeDAS stations, DS reproduced the observed distribution of precipitation well on the Pacific Ocean side of Japan (the Kii Peninsula and Shikoku and Kyushu Islands; Fig. 6). In contrast, GPCP and JRA-55 could not reproduce the distribution very well in these areas because of their low resolutions. The underestimation of precipitation by DS in and around the Okinawa Islands
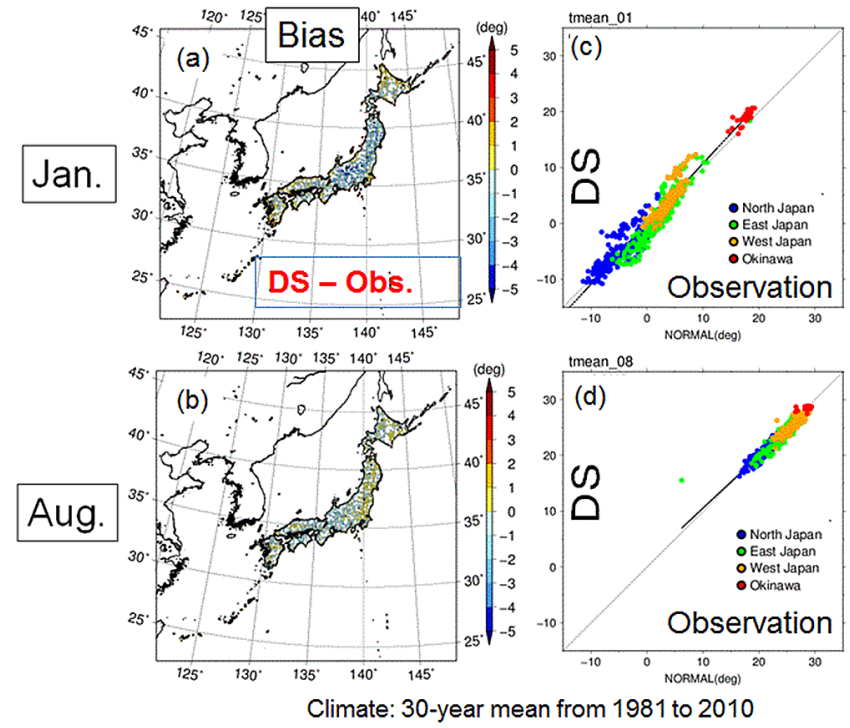

Fig. 5. Monthly mean temperature biases compared with the climatology. Monthly DSJRA-55 (DS) temperature biases (DS - observations) in Japan in (a) January and (b) August. Scatter diagrams of DSJRA-55 temperature anomalies versus observations for (c) January and (d) August. 

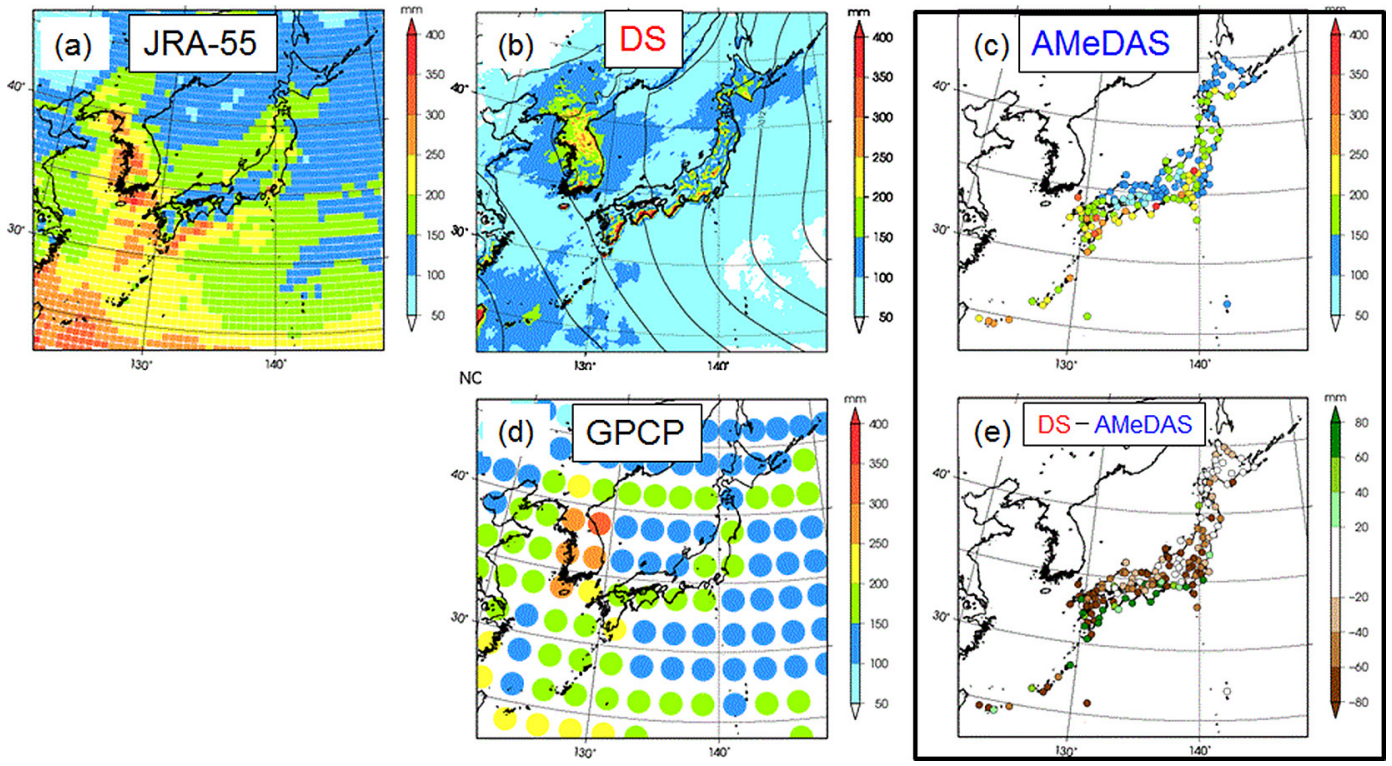

Fig. 6. Monthly mean precipitation in August. Mean August precipitation: (a) JRA-55; (b) DSJRA-55; (c) AMeDAS observations; (d) GPCP estimations; and (e) difference between DSJRA-55 and AMeDAS.

(a)

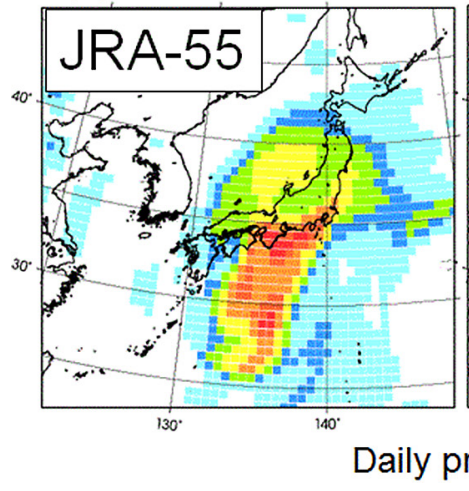

(b)

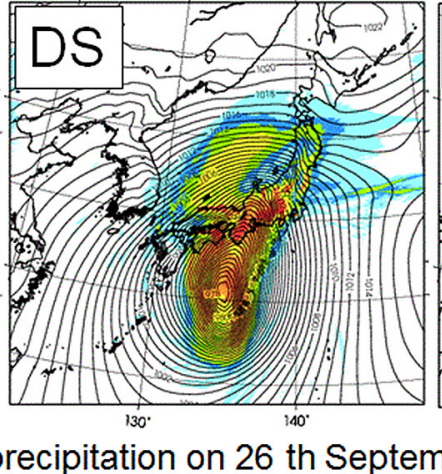

(c)

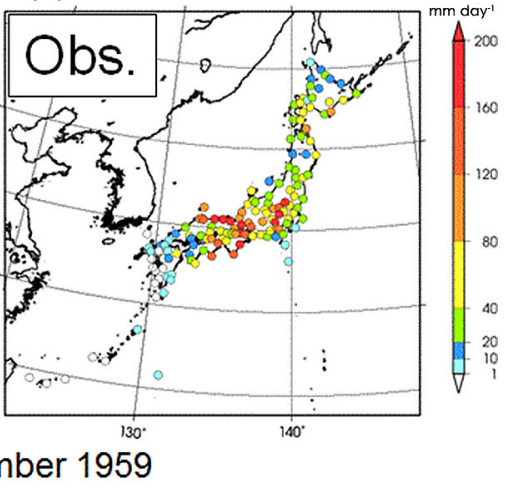

Fig. 7. Reproducibility of precipitation during Typhoon Vera (1959). Distribution of mean precipitation on 26 September 1959: (a) JRA-55; (b) DSJRA-55; and (c) SYNOP observations.

may be due to their nearness to the model domain's lateral boundary and the insufficient resolution of SST to represent well the flow of the Kuroshio current.

\section{Application of DS to past events}

\subsection{Reproducibility of an extreme event}

JRA-55 data extend back to 1958, making it possible to analyze global circulation from that time; furthermore, DS makes it possible to reproduce and evaluate small-horizontal-scale phenomena such as small-scale orographic precipitation. Thus, application of this high-temporal (every hour) and high-spatialresolution $(5 \mathrm{~km}$ horizontal) dataset to both statistical climate studies and studies of particular events is expected.

We take Typhoon Vera (1959; Ise-wan Typhoon in Japanese) as an example. Vera caused more than 5,000 deaths and missing. It formed east of the Mariana Islands on 21 September 1959 and moved northwestward. It made landfall on Shionomisaki in the Honshu island on 26 September, with its peak intensity of central pressure $929 \mathrm{hPa}$. Strong winds were observed in the areas where the typhoon passed nearby. At Irako station, the maximum wind of $45.4 \mathrm{~m} \mathrm{~s}^{-1}$ and the maximum gust of $55.3 \mathrm{~m} \mathrm{~s}^{-1}$ were observed. We compared daily precipitation on 26 September 1959 among
JRA-55, DS, and observations (Fig. 7). DS reproduced the high (>200 $\mathrm{mm}$ ) observed precipitation with a realistic distribution on Shikoku Island, the Kii Peninsula, in inland mountainous areas, and on the Japan Sea side of western Japan.

\subsection{Other applications}

We evaluated long-term trends of changes in annual precipitation by comparing DS data with land-surface observations (Fig. S3), and we similarly evaluated long-term trends of changes in the annual maximum daily precipitation (Fig. S4). Further investigation on the distribution between atmospheric circulation and its causing factor are expected by using DS along with observational data.

Probable daily maximum precipitations defined by using the generalized extreme value (GEV) distribution were estimated by using DS and AMeDaS (Figs. S5 and S6). The GEV shape parameters were given by fitting a specific linear function to the annual maximum values of daily precipitations for the return period of about 50 years.

Historical surface observational data such as SYNOP and AMeDAS data may have gaps in the observation period, station location changes, and instrument changes. This inhomogeneity can be detected and evaluated by comparing the observational data with homogeneous DS data. 


\section{Summary}

We outlined and evaluated the DSJRA-55, a dynamical regional downscaling of the JRA-55 reanalysis, and described some of its possible applications. Annual changes of temperature and precipitation were mostly reproduced well by DSJRA-55 compared with observational data. However, DSJRA-55 showed biases in some seasons and regions, as well as less frequent HRpD and $\mathrm{HRpH}$, compared with observations.

On the whole, DSJRA-55 reproduced orographic precipitation, heavy rain events in summer, and other small-scale meteorological phenomena well. Such phenomena cannot be reproduced by JRA- 55 because of its coarser horizontal resolution. DSJRA-55 is expected to be useful for analyses of individual events and for statistical analyses of climate. Although in this paper, we focused on temperature and precipitation, DSJRA-55 will also be useful for investigations of many other meteorological variables, including winds, humidity and lower cloud cover. Therefore, DSJRA-55 will be valuable for applied studies in fields such as climatology, hydrology, and agriculture.

Formerly, only historical weather charts and small sets of observational data have been available for studying past extreme events, such as Typhoon Vera (1959). Now, for such studies, DSJRA-55 provides uniformly gridded meteorological data produced by a state-of-the-art mesoscale numerical prediction model using meteorologically consistent initial fields from the highquality global JRA-55 reanalysis.

Additional evaluations of the quality of DSJRA-55 data are needed, and we encourage researchers to use DSJRA-55 for various applications.

\section{Acknowledgments}

DSJRA-55 was developed with the cooperation of many divisions of JMA. Members of the Climate Prediction Division (CPD), the Meso-model group of the Numerical Prediction Division (NPD), the Regional Climate Model group of MRI gave us useful advice on the model and system configuration. Members of the CPD and the Diagnostic Prediction group, headed by Dr. Teruyuki Kato of MRI, gave us useful comments on the evaluations. The Programming section of the NPD gave us special consideration for the use of the supercomputer system, making it possible for DSJRA-55 to be completed in time for schedule. All groups of the CPD gave us special consideration for archiving many DSJRA-55 products. We sincerely appreciate all of these invaluable contributions.

Edited by: H. Kusaka

\section{Supplementary information}

All abbreviations are defined in Table S1.

Supplementary Figs. S1 to S6 are attached.

\section{References}

Adler, R. F., G. J. Huffman, A. Chang, R. Ferraro, P.-P. Xie, J. Janowiak, B. Rudolf, U. Schneider, S. Curtis, D. Bolvin, A. Gruber, J. Susskind, P. Arkin, and E. Nelkin, 2003: The Version-2 Global Precipitation Climatology Project (GPCP) monthly precipitation analysis (1979-present). J. Hydrometeor., 4, 1147-1167.

Ishii, M., A. Shouji, S. Sugimoto, and T. Matsumoto, 2005: Objective Analyses of Sea-Surface Temperature and Marine Meteorological Variables for the 20th Century using ICOADS and the Kobe Collection. Int. J. Climatol., 25, 865-879.

JMA, 2013a: Global Warming Projection, Volume 8. 145 pp. (Available online at http://ds.data.jma.go.jp/tcc/tcc/products/ gwp/gwp.html, accessed 3 August 2015).

JMA, 2013b: Outline of the Operational Numerical Weather Prediction at the Japan Meteorological Agency. Appendix to WMO Technical Progress Report on the Global DataProcessing and Forecasting System and Numerical Weather Prediction, $188 \mathrm{pp}$. (Available online at http://www.jma. go.jp/jma/jma-eng/jma-center/nwp/nwp-top.htm, accessed 3 August 2015).

Kanamitsu, M., and H. Kanamaru, 2007: Fifty-Seven-Year California Reanalysis Downscaling at $10 \mathrm{~km}$ (CaRD10). Part I: System Detail and Validation with Observations. J. Climate, 20, 5553-5571.

Kobayashi, S., Y. Ota, Y. Harada, A. Ebita, M. Moriya, H. Onoda, K. Onogi, H. Kamahori, C. Kobayashi, H. Endo, K. Miyaoka, and K. Takahashi, 2015: The JRA-55 Reanalysis: General specifications and basic characteristics. J. Meteor. Soc. Japan, 93, 5-48.

Onogi, K., J. Tsutsui, H. Koide, M. Sakamoto, S. Kobayashi, H. Hatsushika, T. Matsumoto, N. Yamazaki, H. Kamahori, K. Takahashi, S. Kadokura, K. Wada, K. Kato, R. Oyama, T. Ose, N. Mannoji, and R. Taira, 2007: The JRA-25 reanalysis. J. Meteor. Soc. Japan, 85, 369-432.

Saito, K., T. Fujita, Y. Yamada, J. Ishida, Y. Kumagai, K. Aranami, S. Ohmori, R. Nagasawa, S. Kumagai, C. Muroi, T. Kato, H. Eito, and Y. Yamazaki, 2006: The Operational JMA Nonhydrostatic Mesoscale Model. Mon. Wea. Rev., 134, 1266-1298.

Manuscript received 26 August 2015, accepted 25 November 2015 SOLA: https://www.jstage.jst.go.jp/browse/solal 